هيدروكيميائية ونوعية المياه لمجموعة من الآبار المنتشرة في منطقة وانة شمال العراق

$$
\begin{aligned}
& \text { حازم جمعة محمود } \\
& \text { مركز بحوث السدود والدوارد المائية } \\
& \text { جامعة الموصل }
\end{aligned}
$$

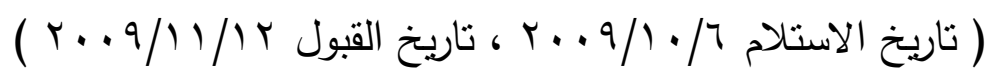

$$
\begin{aligned}
& \text { الملخص }
\end{aligned}
$$

يهتم البحث الحالي بدراسة هيدروكيميائية المياه لمجموعة من الآبار السطحية في منطقة وانة، وتحديد

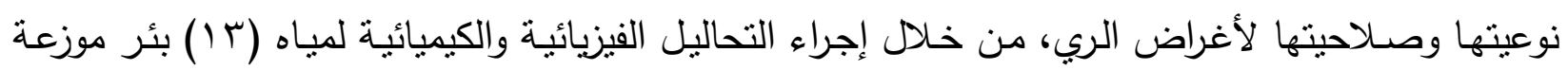
على منطقة الدراسة.

وقد أظهرت نتائج البحث وجود عاملين رئيسين يسيطران على هيدروكيميائية المياه في آبار منطقة

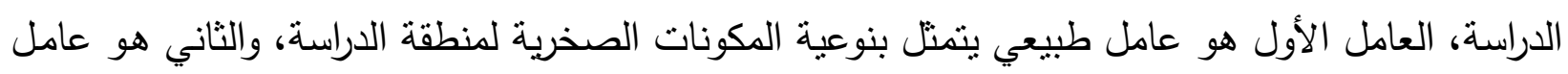

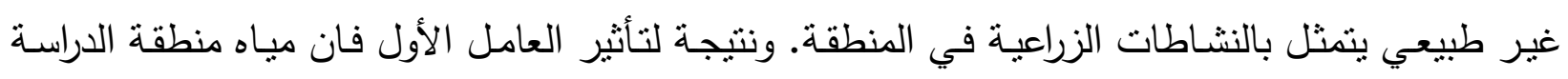

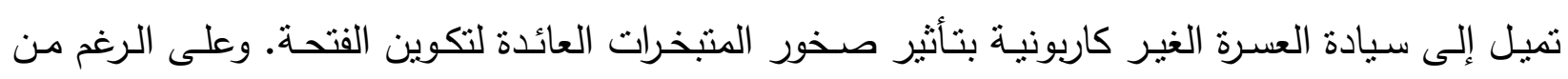
التأثير الكبير لصخور تكوين الفتحة على نوعية المياه في منطقة الدراسة إلا أن التغذية المباشرة من مياه

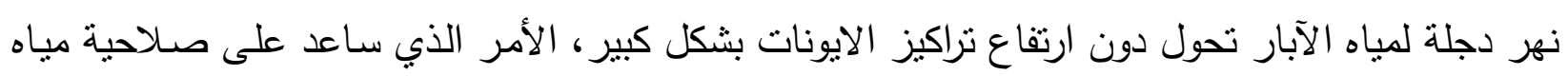

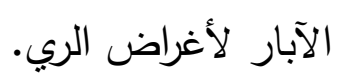

\title{
Hydrochemistry and Water Quality of Some Wells Distributed at Wana Area Northern Iraq
}

\author{
Hazim J. M. Al-Nuaimy \\ Dams and Water Resources Research Center \\ Mosul University
}

\begin{abstract}
The present work, deals with hydrochemistry and water quality of some shallow wells in Wana area, northern Iraq and its validity for irrigation, through the physical and chemical analyses of 13 water samples selected from these wells distributed in the study area.
\end{abstract}


The results revealed that there are two factors controlling the hydrochemistry of water in the area. The first is natural factor represented by type of rock components of the studied area, and the second is anthropogenic factor which is human activities. Owing to the natural factor, the analyzed water tend to be of non carbonate hardness by the influence of the evaporates of Fat'ha formation. Despite the great influence of Fat'ha formation rocks on water quality in the area, however the direct feeding of Tigris river to the well waters prevents the increasing of the concentration of ions and this made these waters valid for irrigation purposes.

\section{المقدمة}

تعتمد مجالات استخدام المياه الجوفية على نوعيتها والتي بدورها تعتمد على خصائصها الكيميائية، لذا

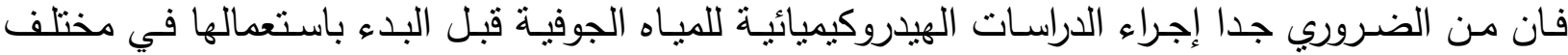
المجالات، خاصة أن المياه الجوفية تمر عبر الفراغات والمسامات للطبقات الصخرية ولذلك فإنها غالبا ما تمتاز بارتفاع تراكيز الايونات الكيميائية مقارنة بمياه الأنهار (Todd, 1980).

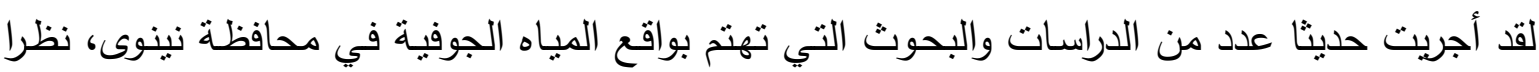
لأهمية هذا الموضوع، خاصـة بعد بروز مسالة الأمن المائي والتحديات المستقبلية في ظل إقامـة السدود التركية. إلا انه لا تزال هناك الكثير من المناطق التي لم تحضى بالاهتمام والدراسة والتي لا يوجد لها بيانات كافية عن كمية ونوعية المياه الجوفية ومن ضمنها مناطق تمتاز بوجود أعداد كبيرة من الآبار وبكميات وفيرة من المياه، وتستعمل في مختلف الججالات دون أن يتم إجراء أي دراسـة عليها في سبيل تحديد نوعيتها ومعرفة ملائكتها للاستخدامات المختلفة، مثال ذلك منطقة الدراسة الحالية الواقعة ـ0 كم شمال غرب مدينة الموصل والمتمثلة بالأراضي الزراعية الممتدة بمحاذاة نهر دجلة والمحصورة بين مركز ناحية وانة وقرية دير

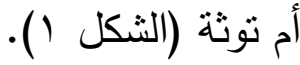

تتمثل منطقة الدراسة من الناحية الجيولوجية بترسبات المصاطب النهرية، وبالتحديد المرحلة الرابعة من المصاطب النهرية (AL-Dabbagh and AL-Naqib, 1991)، والتي تتكون من الطين والغرين والرمل والحصى، والطبقة الرملية الحصوية تعد هي الطبقة الحاوية للمياه في المنطقة. وتمند تحت الترسبات النهرية طبقات تكوين الفتحة، التي تتكثف في جميع المناطق المحيطة بالترسبات النهرية، وتتكون المكاثف التفاه الصخرية من تكوين الفتحة في منطقة الدراسة من دورات رسوبية من المارل وطبقات سميكة من الجبسوم والحجر الجيري.

تتنتر ضمن الترسبات النهرية في المنطقة عدد كبير من الآبار التي تتغذى من مياه نهر دجلة وتستعمل في الزراعة بشكل رئيس. تهدف الدراسة الحالية إلى دراسة مياه هذه الآبار من الناحية الهيدروكيميائية وتحديد نوعيتها ومدى صلاحيتها لأغراض الري. 


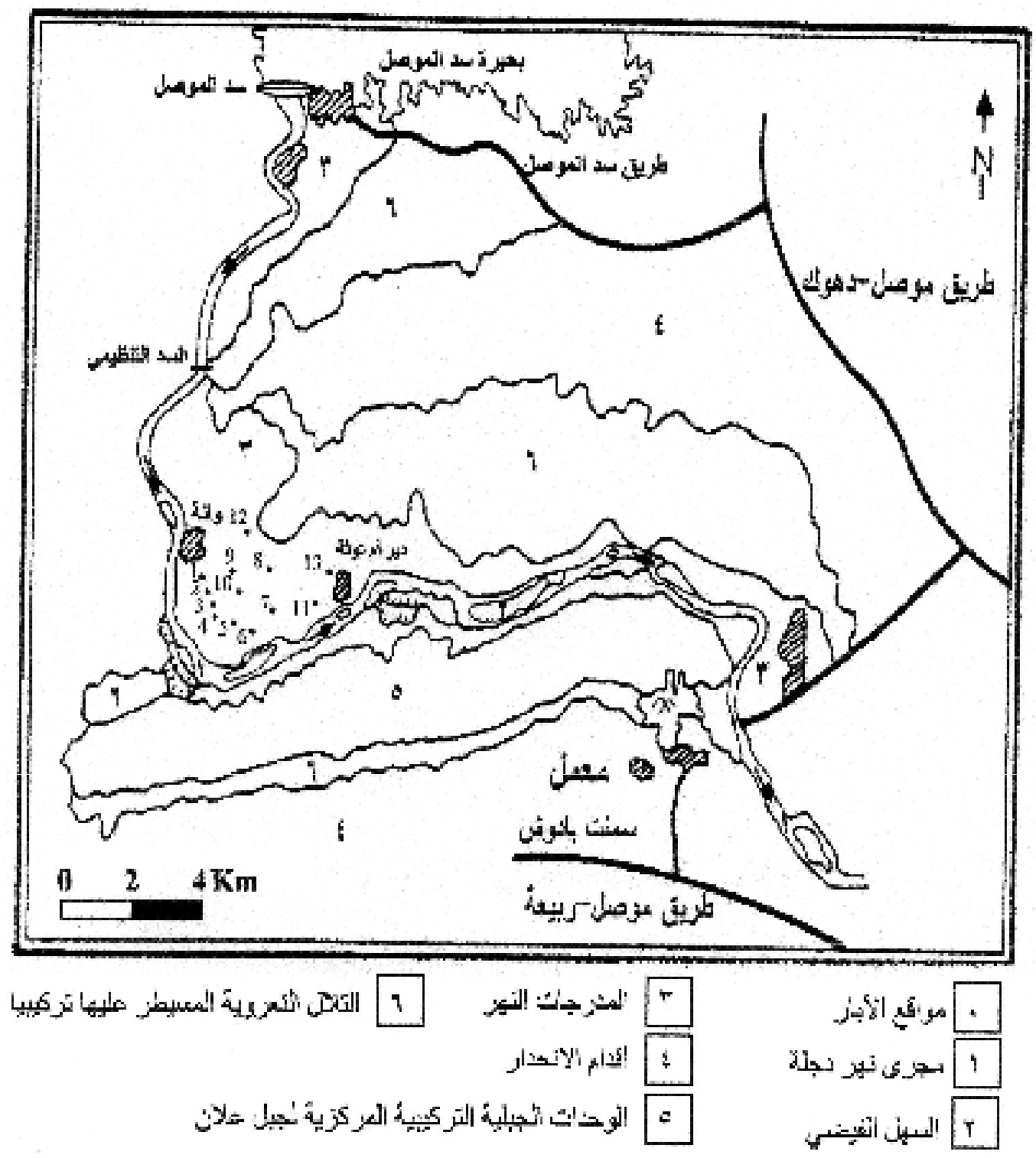

الثكل (: خارطة جيومورفولوجية أولية (الطائي، ب .. r) موضح عليها مواقع آبار

\section{النمذجة وطرق العمل}

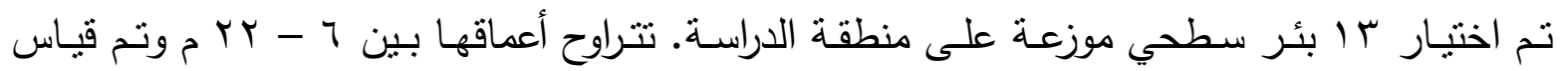

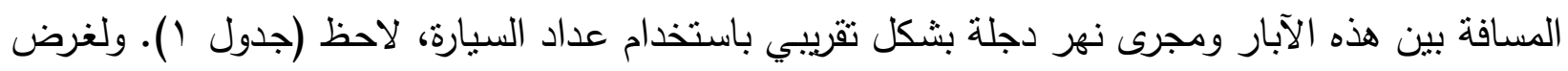

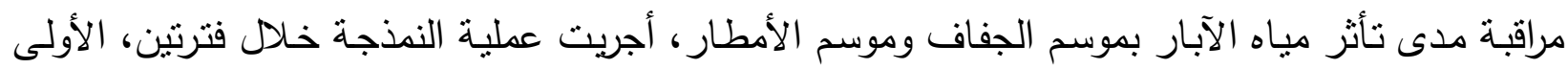

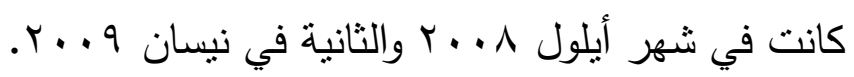
أجريت قباسات الدالة الحامضية (pH) والايصالية الكهربائية (E.C.) والأملاح الكلية الذائبة (T.D.S)

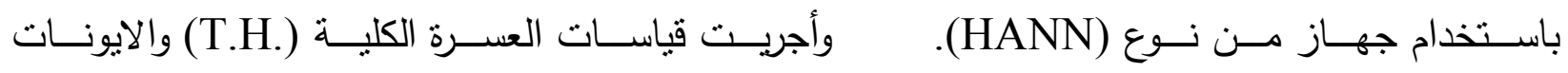
باستخدام طرق النسحيح، وتم قياس ( $\left.{ }^{-} \mathrm{Cl}^{-}, \mathrm{HCO}_{3}^{-}, \mathrm{Mg}^{+2}, \mathrm{Ca}^{+2}\right)$ 
فقد تم قياسهما باستخدام جهاز طيف اللهب. أجريت القياسات في مختبر مركز بحوث السدود والموارد المائية ما عدا قياس (NO وحسب (Jenkins, et. al , 1980) و (عباوي و حسن، . 199).

الجدول ا : مستوى مياه آبار الدراسة والمسافة بينها وبين نهر دجلة

\begin{tabular}{|c|c|c|}
\hline بعد البئر عن النهر(م) & عمق المياه من السطح(م) & رقم البئر \\
\hline$\leqslant 0$. & 7 & 1 \\
\hline $0 \ldots$ & 9 & $T$ \\
\hline $0 \leqslant$. & 11 & $\mu$ \\
\hline$V_{\cdots} \cdot$ & 11 & 4 \\
\hline $1 \ldots$ & 1. & 0 \\
\hline $7 \ldots$ & $\Lambda$ & 7 \\
\hline $1 \ldots$ & 10 & V \\
\hline $1 \leqslant \ldots$ & $r \cdot$ & $\Lambda$ \\
\hline $10 .$. & 1. & 9 \\
\hline $1 \ldots$ & 1. & 1 . \\
\hline $1 \ldots$ & 9 & 11 \\
\hline r... & 17 & IT \\
\hline $9 \ldots$ & TY & 14 \\
\hline 979 & IT & المعدل \\
\hline
\end{tabular}

\section{النتائج والمناقشة}

يبين (الجدول r) الخصائص الفيزيائية لنماذج مياه أبار منطقة الدراسة وخلال مرحلتي النمذجة وفيما

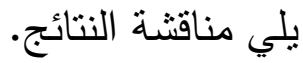

الجدول r: الخصائص الفيزيائية لياه آبار منطقة الدراسة خلال فترتي الندذجة

\begin{tabular}{|c|c|c|c|c|c|c|c|c|}
\hline \multicolumn{4}{|c|}{ نهاية موسم الأمطار } & \multicolumn{4}{|c|}{ نهاية موسم الجفاف } & \multirow[b]{2}{*}{ الآبار } \\
\hline $\begin{array}{l}\text { E.C. } \\
(\mu s)\end{array}$ & $\mathrm{pH}$ & $\begin{array}{c}\text { T.H } \\
\text { (ppm) }\end{array}$ & $\begin{array}{l}\text { T.D.S } \\
\text { (ppm) }\end{array}$ & $\begin{array}{l}\text { E.C. } \\
(\mu \mathrm{s})\end{array}$ & $\mathrm{pH}$ & $\begin{array}{c}\text { T.H } \\
\text { (ppm) }\end{array}$ & $\begin{array}{l}\text { T.D.S } \\
\text { (ppm) }\end{array}$ & \\
\hline or. & $V . V$ & $r \wedge \varepsilon$ & r.. & TOV & 7.9 & rAl & $1 \times 9$ & 1 \\
\hline Vo. & $\vee . \wedge$ & $\varepsilon Y Y$ & rᄉ. & TYY & $V . Y$ & rVI & 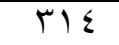 & $T$ \\
\hline $9 \wedge$. & $V .0$ & OrT & $\leqslant 9$. & VI. & V.1 & 0.9 & rᄉr & $r$ \\
\hline $11 \pi$. & V.r & 094 & ov. & ヘ9V & V.1 & $7 Y 7$ & $\leqslant 0$. & $\varepsilon$ \\
\hline $1 \% \ldots$ & $V . r$ & $v_{\ldots}$ & 70. & $1.7 \pi$ & $V_{.}$. & $T \leqslant$. & OrV & 0 \\
\hline 19. & V.1 & $\varepsilon \varepsilon$. & $\varepsilon \varepsilon$. & 090 & $V . Y$ & हार & rq. & 7 \\
\hline IVV. & V.7 & $9 \vee \leqslant$ & $\Lambda \wedge$. & $1 \leqslant 9 V$ & v. & 1.10 & VI. & $V$ \\
\hline$r \cdot 1 \cdot$ & V.V & $9 Y T$ & $1 \cdot r$ & $I V \leqslant Y$ & $V . r$ & 91. & NVO & $\Lambda$ \\
\hline 94. & V.7 & $\varepsilon \wedge T$ & $\leqslant 7$. & $\vee \wedge \varepsilon$ & V.r & $\sum T Y$ & rqY & 9 \\
\hline 97. & V.0 & OYI & $\sum 9$. & $\Lambda \cdot 1$ & V.r & 077 & §. & 1. \\
\hline $1 \leqslant \varepsilon$. & $V . \Sigma$ & 771 & VY. & $11 \leqslant$. & V.r & 179 & OVT & 11 \\
\hline 171. & V.P & 97. & $\Lambda \Sigma$. & $1 \% V 7$ & $V_{.}$ & $1 \ldots 1$ & 791 & ir \\
\hline IVT. & $V . r$ & 97. & 1.. & (1T47 & $V . Y$ & 9.1 & $7 V$. & $1 T$ \\
\hline ITHA & $V . \Sigma$ & 70. & $\pi$ Tr. & 99. & $V . Y$ & $\leqslant 91$ & $\sum 9 \wedge$ & المعدل \\
\hline
\end{tabular}


الدالة الحامضية (pH): (الد)

تؤُثر قيم الدالة الحامضية بشكل مباشر على كيميائية المياه، وان الانخفاض والارتفاع في الدالة الحامضية قد يحدث بشكل طبيعي، بسبب حركة المياه الجوفية واختلاطها مـع نوعيات مختلفة من المياه ومرورها عبر طبقات صخرية مختلفة (Sen, 2008)، وقد يحدث التذبذب في الدالة الحامضية نتيجة

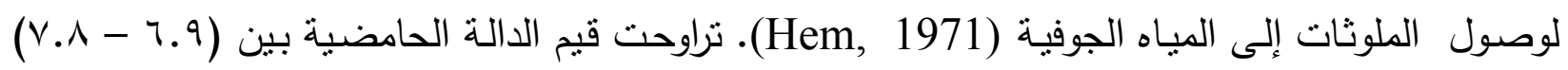

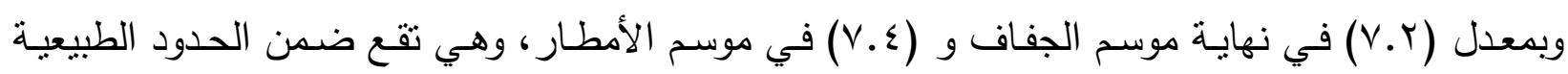
والمناسبة للاستخدامات المختلفة.

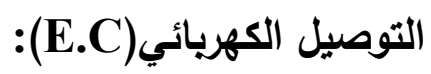

تعكس قيم التوصيل الكهربائي محتوى المياه من الأملاح المذابة بشكل نسبي وتتراوح بين عشرات من

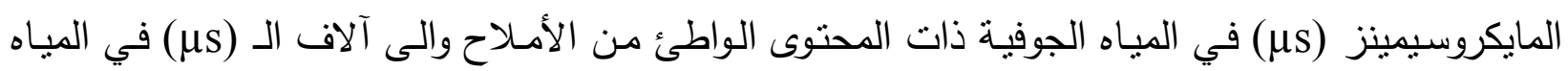
الجوفية ذات المحتوى العالي من الأمـلاح (Freez and Cherry, 1979). وان العلاقة بين الكين التوصيل

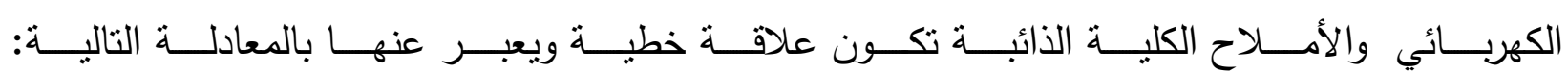
TDS $=\mathrm{A} * \mathrm{EC}$

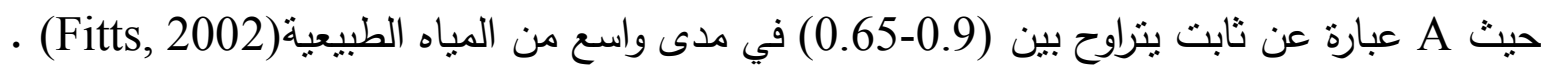

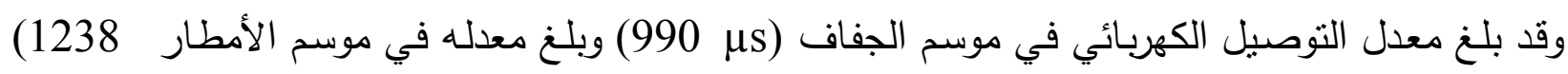

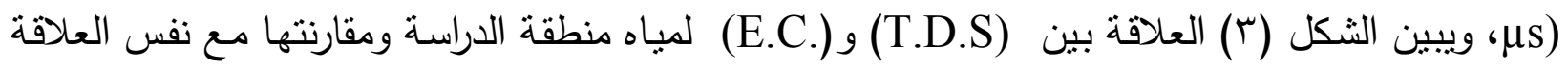

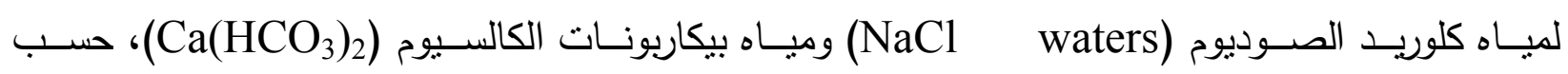
.( Langmuir and Mahoney,1985. in Langmuir,1997)

\section{الأملاح الكلية الذائبة (T.D.S):}

تعبر قيم (T.D.S) عن ملوحة المياه، وهي من الصفات الفيزيائية المهمة التي يعتمد عليها في تقييم

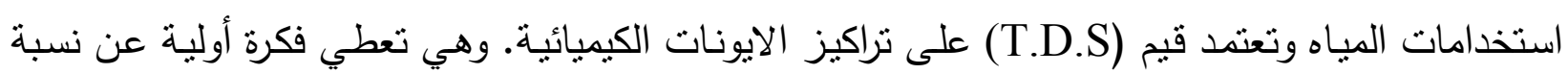

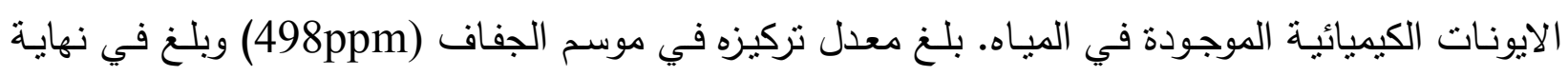

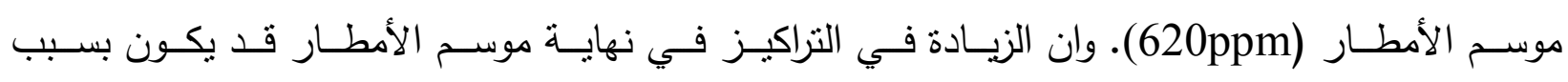
عمليات الغسل والإذابـة للأمسلاح الموجودة في الطبقات الواقعـة فوق مسنوى الميـاه الجوفيـة، بواسطة مياه

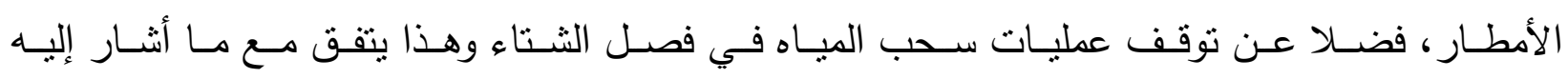

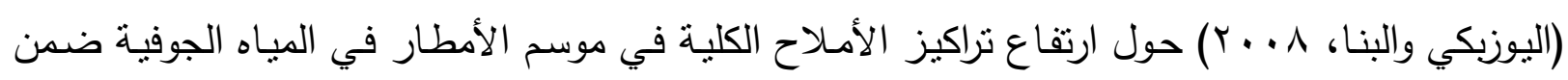

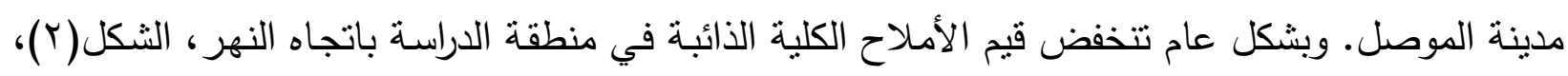

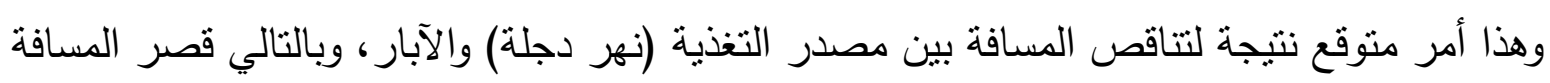
التي تقطعها المياه ضمن الترسبات قبل الوصول إلى الآبار القريبة. 


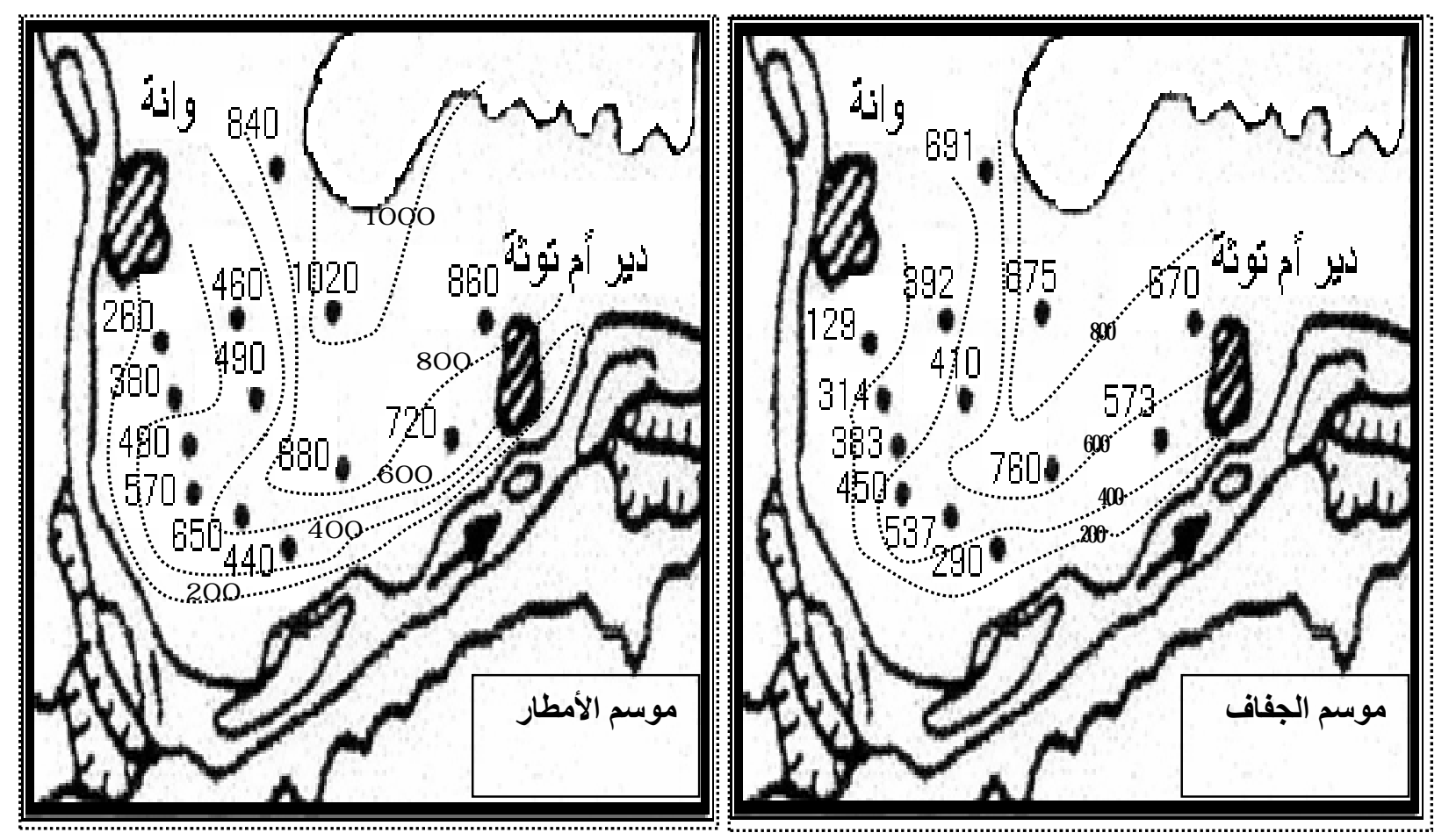

الشكل ؟ منطقة الدر اسة موضح عليها مو اقع الآبار المدروسة والخطوط الكنتورية لقيم

العسرة الكلية (T.H):

تعتمد قيمة العسرة الكلية على تراكيز الايونات المتعددة التكافؤ، ويعد الكالسيوم والمغنيسيوم من أكثر الايونـات المسببة للعسرة في المباه الطبيعيـة (Manahan, 2005). تراوحت قيم العسرة الكلية في آبـار الدراسة بين (ppm 1035-281) وبمعدل (ppm777) في نهاية موسم الجفاف و ( •.ppm70) في نهاية (Todd, موسم الأمطار • تتأثز قيم العسرة بشكل رئيس بطبيعة مكونات الطبقات الصخرية الحاوية للمياه (1980، وتتكل صخور المتبخرات والكاربونات والمكونات الفتاتية العائدة لتكوين الفتحة المصدر الرئيسي لارتفاع قيمـة العسرة الكليـة في بعض آبـار منطقة الدراسـة. وتصنف ميـاه منطقة الدراسـة اعتمـادا على قيم العسرة الكلية ضمن صنف المياه العسرة جدا لاحظ (الجدول ب).

الجدول r: تصنيف عسرة المياه حسب ( Todd and Mays, 2005 )

\begin{tabular}{|c|c|}
\hline العسرة الكلية بدلالة كاربونات الكالسيوم & صنف المياه \\
\hline اقل من Vo & يسر \\
\hline $75-150$ & عسر نسبيا \\
\hline $150-300$ & عسر \\
\hline أكثر من · · & عسر جدا \\
\hline
\end{tabular}




\section{الخصائص الكيميائية}

تتمثل الخصـائص الكيميائيسة للميـاه بمحتواهـا مـن الايونـات السـالبة والموجبـة، وتعتمــ تراكيز هذهـ الايونات على عدد من العوامل من أهمها نوعية الصخور الملامسة للمياه (Devilliers, 2005) وفيما يلي لياهي

مناقتشة الايونات الرئيسية الني تم تحليلها في مياه آبار منطقة الدراسة، (جدول ع).

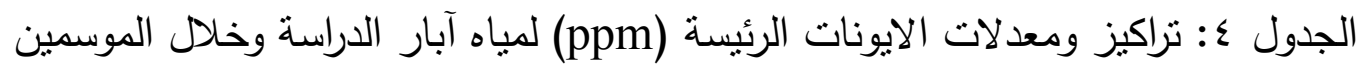

\begin{tabular}{|c|c|c|c|c|c|c|c|c|c|}
\hline $\mathrm{NO}_{3}$ & $\mathrm{CL}^{-}$ & $\mathrm{SO}_{4}{ }^{-2}$ & $\mathrm{HCO}_{3}{ }^{-}$ & $\mathrm{K}^{+}$ & $\mathrm{Na}^{+}$ & $\mathrm{Mg}^{+2}$ & $\mathrm{Ca}^{+2}$ & رقم البئر & الموسم \\
\hline 7 & $\Lambda \varepsilon$ & 00 & 109 & $r$ & 10 & TV & 71 & 1 & \multirow{13}{*}{ 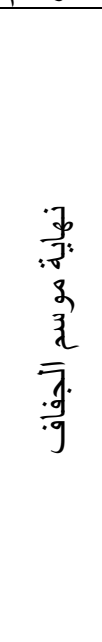 } \\
\hline$\mu$ & $\Sigma \wedge$ & $r \cdot T$ & 104 & $r$ & rT & TV & $1 \cdot \varepsilon$ & $r$ & \\
\hline$\varepsilon$ & $9 \leq$ & TrV & 170 & $\varepsilon$ & $\varepsilon \wedge$ & rq & $1 \varepsilon$ & $\mu$ & \\
\hline$\Gamma$ & $V Y$ & $\varepsilon \ldots$ & $1 \leqslant 7$ & 0 & Tr & $\leqslant 7$ & 110 & $\varepsilon$ & \\
\hline 0 & 97 & $\sum 9 \wedge$ & 119 & 7 & $\varepsilon \xi$ & $V T$ & ITY & 0 & \\
\hline$\varepsilon$ & $\Lambda \wedge$ & $r \leqslant r$ & IYY & $\varepsilon$ & $r \varepsilon$ & ro & IY & 7 & \\
\hline$V$ & $Y . T$ & $\wedge \backslash 1$ & $1 \wedge \mu$ & 11 & 90 & 114 & r. & $V$ & \\
\hline 0 & $Y . T$ & גז & r\A & 0 & 18. & $9 V$ & TrM & $\Lambda$ & \\
\hline$\Gamma$ & $V$. & 199 & TrY & $\varepsilon$ & Vo & $r v$ & IY & 9 & \\
\hline$r$ & 97 & אדצr & 170 & $r$ & $\varepsilon r$ & 77 & 111 & 1. & \\
\hline$\Lambda$ & $11 \varepsilon$ & 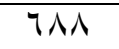 & 190 & $\Lambda$ & 7. & $V T$ & TYA & 11 & \\
\hline$r$ & ITV & $V V V$ & 119 & 0 & Vᄉ & 10 & YII & IT & \\
\hline$\Lambda$ & ITI & $7 / Y$ & $1 V 1$ & $\Lambda$ & Tr & $7 \wedge$ & $r \leqslant q$ & $1 T$ & \\
\hline 0 & 111 & $\varepsilon V T$ & $1 \wedge$. & 0 & $O V$ & 7. & 179 & \multicolumn{2}{|c|}{ المعدل } \\
\hline $\mathrm{NO}_{3}$ & $\mathrm{CL}^{-}$ & $\mathrm{SO}_{4}{ }^{-2}$ & $\mathrm{HCO}_{3}^{-}$ & $\mathrm{K}^{+}$ & $\mathrm{Na}^{+}$ & $\mathrm{Mg}^{+2}$ & $\mathrm{Ca}^{+2}$ & رقم البئر & \multirow{14}{*}{ 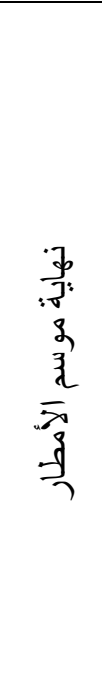 } \\
\hline 0 & ry & 107 & 171 & $r$ & $1 \leq$ & rq & 77 & 1 & \\
\hline r & $r$. & rVA & 107 & $r$ & r & $\varepsilon \Lambda$ & 9. & $r$ & \\
\hline$\varepsilon$ & $\varepsilon 7$ & $\varepsilon \cdot \varepsilon$ & 101 & $\Gamma$ & rᄉ & $\varepsilon V$ & ITy & $\mu$ & \\
\hline$\varepsilon$ & $7 Y$ & $\varepsilon \wedge Y$ & $|V|$ & $\mu$ & or & $0 \wedge$ & $1 \leqslant Y$ & $\varepsilon$ & \\
\hline$\mu$ & 7. & $0 \wedge \Lambda$ & 177 & $r$ & 77 & $V T$ & 17. & 0 & \\
\hline V & r & $\Gamma .0$ & 177 & 9 & rᄉ & rq & 114 & 7 & \\
\hline 0 & $V$. & $94 \leq$ & 19. & 0 & 1.7 & 1 o & 171 & V & \\
\hline$\varepsilon$ & $V \varepsilon$ & 900 & $r .0$ & $\varepsilon$ & 17. & $1 \mathrm{~T}$ & TYA & $\Lambda$ & \\
\hline$r$ & TV & r9o & $1 \wedge V$ & $\Gamma$ & 7. & 00 & $1 \cdot \varepsilon$ & 9 & \\
\hline$r$ & $r$. & $\varepsilon \leqslant 7$ & $|V|$ & $\mu$ & or & $\leqslant 9$ & IYA & 1. & \\
\hline 7 & 0. & 711 & $r \varepsilon \varepsilon$ & 0 & 110 & $V_{1}$ & $1 \leqslant \Lambda$ & 11 & \\
\hline$r$ & $\sum \wedge$ & $\Lambda \Psi \varepsilon$ & YTV & $\mu$ & 94 & $\lambda \mu$ & $r \leqslant \Lambda$ & IT & \\
\hline 7 & 0. & AYr & Y^క & 0 & 94 & 90 & YrA & $1 T$ & \\
\hline$\varepsilon$ & $\varepsilon 0$ & 000 & $19 \varepsilon$ & $\varepsilon$ & $V \cdot$ & $7 V$ & 101 & \multicolumn{2}{|c|}{ المعدل } \\
\hline
\end{tabular}

(الكالسيوم (Ca)

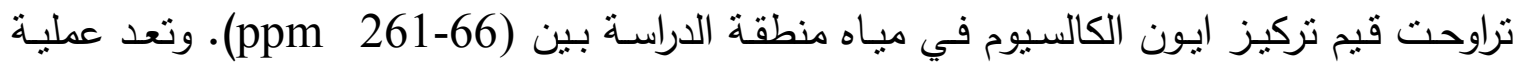

التجوية الكيميائية للصخور الكاربوناتية، وصخور المتبخرات المصدر الرئيسي لهذا الايون في المياه الطبيعية (Bouwer, 1978)، وتتمثل هذه الصخور في منطقة الدراسـة بصخور طبقات تكوين الفتحة والمكونات

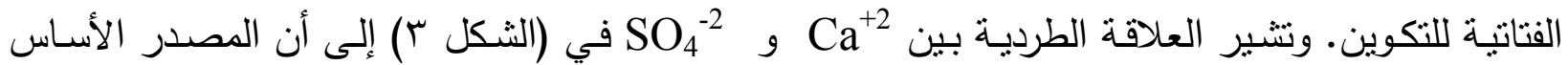


للكالسيوم في المنطقة هو صخور المنبخرات لتكوين الفتحة، ويؤيد ذلك أيضـا علاقة الربط الموجبة القويـة

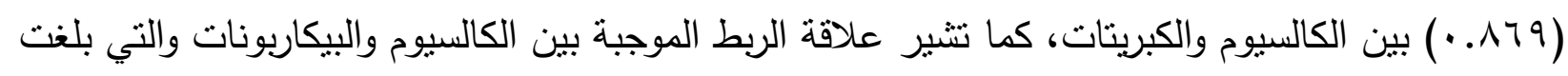
( ع به. •) إلى المصدر الثاني للكالسيوم في صخور الفتحة والمتمثلة بالصخور الكاربوناتية. المغنيسيوم ()

تعد صخور الدولومايت من أهم المصادر الطبيعية لارتفاع تركيز ايون المغنيسيوم في المياه الجوفية وتتير العلاقة الطردية بين المغنيسيوم والبيكاربونات في( الثنك r) إلى صخور الدولومايت كمصدر للمغنيسيوم في مياه منطقة الدراسـة، ويؤيد ذلك علاقة الارتباط الموجبة بين المغنيسيوم وكل من الكالسيوم والبيكاربونـات (جدول 5)، وربمـا نشير العلاقة الموجبة بين المغنيسيوم والكبريتات في (الجدول 5) إلى صخور تكوين الفتحة كمصدر لهذه الايونات في المنطقة.
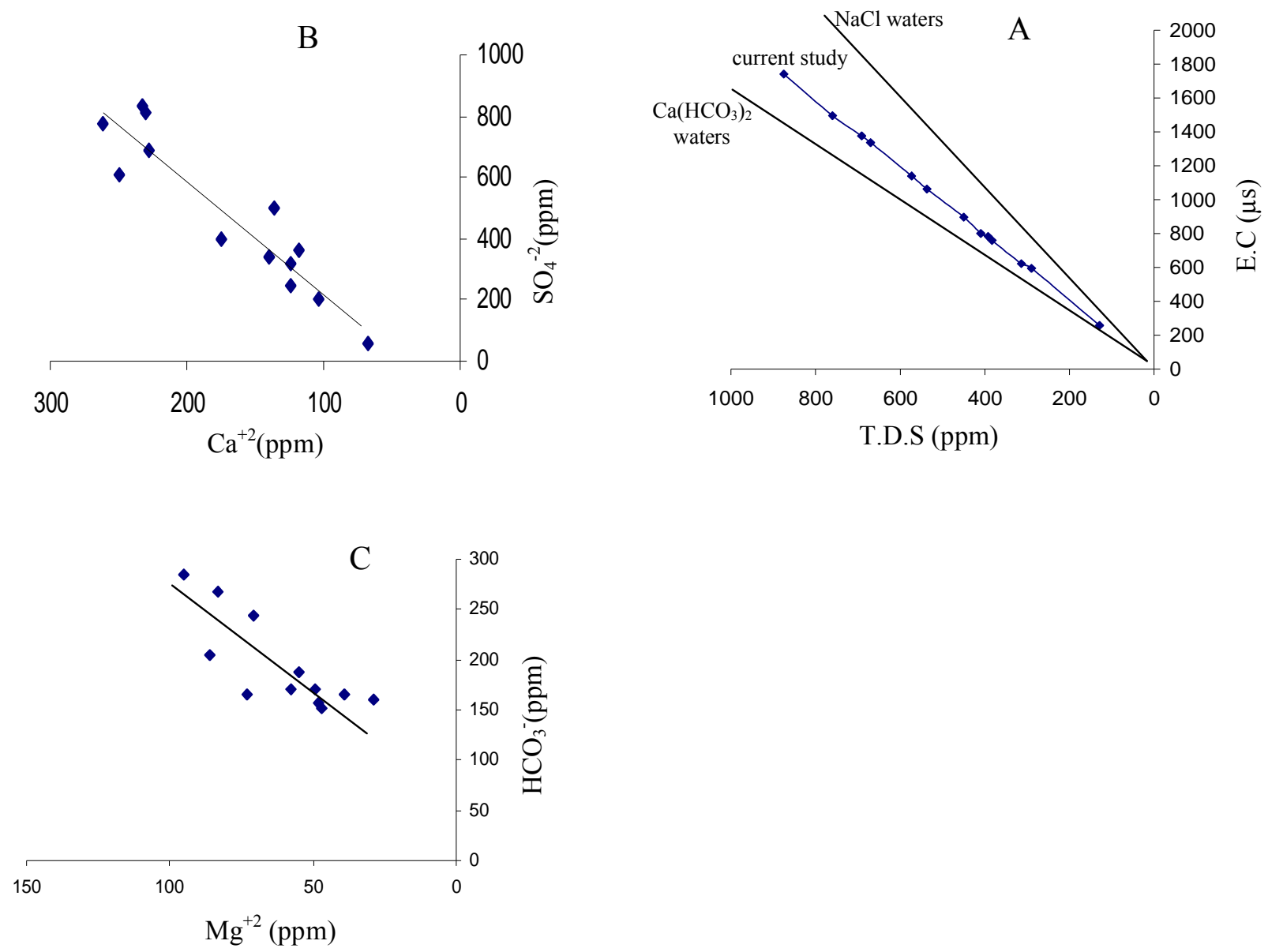

الثكل r:(A)(العلاقة بين الأملاح الكلية والايصالية الكهربائية

(B) العلاقة بين ايون الكالسيوم والكبريتات

العلاقة بين ايون المغنيسيوم والبيكاربونات (C) 


\begin{tabular}{l|l|l|l|l|l|l|l|l|l|l|l|l}
\hline $\mathbf{S O}_{4}^{-2}$ & $\mathbf{H C O}_{3}^{-}$ & $\mathbf{K}^{+}$ & $\mathbf{N a}^{+}$ & $\mathbf{M g}^{+2}$ & $\mathbf{C a}^{+2}$ & $\mathbf{E . C}$ & $\mathbf{p H}$ & $\mathbf{T . H}$ & $\mathbf{T . D . S}$ & Dis. & Dep. & Variables \\
\hline 793 & .575 & .309 & .647 & .683 & .832 & .817 & -.035 & .828 & .818 & .482 & 1.000 & Dep. \\
\hline 634 & .616 & .076 & .621 & .512 & .616 & .592 & -.129 & .617 & .592 & 1.000 & & Dis. \\
\hline 976 & .670 & .324 & .863 & .880 & .815 & 1.000 & .092 & .912 & 1.000 & & & T.D.S \\
\hline 964 & .584 & .496 & .726 & .903 & .943 & .911 & -.142 & 1.000 & & & & T.H \\
\hline 028 & -.054 & -.350 & .115 & .039 & -.264 & .092 & 1.000 & & & & & $\mathbf{p H}$ \\
\hline 976 & .674 & .323 & .861 & .879 & .814 & 1.000 & & & & & & $\mathbf{E . C}$ \\
\hline 869 & .534 & .498 & .624 & .708 & 1.000 & & & & & & & $\mathbf{C a}^{+2}$ \\
\hline 921 & .547 & .407 & .732 & 1.000 & & & & & & & & $\mathbf{M g}^{+2}$ \\
\hline 830 & .743 & .199 & 1.000 & & & & & & & & & $\mathbf{N a}^{+}$ \\
\hline 386 & .129 & 1.000 & & & & & & & & & & $\mathbf{K}^{+}$ \\
\hline 634 & 1.000 & & & & & & & & & & & $\mathbf{H C O}_{\mathbf{3}}^{-}$ \\
\hline 1.000 & & & & & & & & & & & & $\mathbf{S O}_{4}^{-2}$ \\
\hline & & & & & & & & & & & & $\mathbf{C l}^{-}$ \\
\hline & & & & & & & & & & & & $\mathbf{N O}_{\mathbf{3}}^{-}$ \\
\hline
\end{tabular}




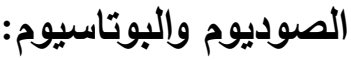

يمتاز الصوديوم والبوتاسيوم بقابليتهما العالية على الذوبان، وان مصادرهما متعددة وقد ينتقلان من

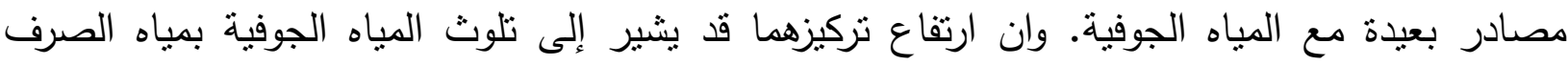

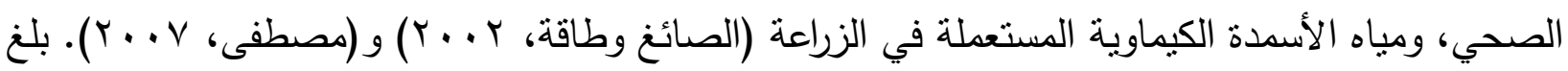
معدل نركيز الصوديوم في موسم الجفاف (ppm 57)، وفي موسم الأمطار بلغ (ppm 70).

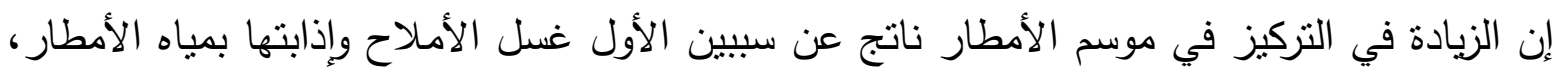

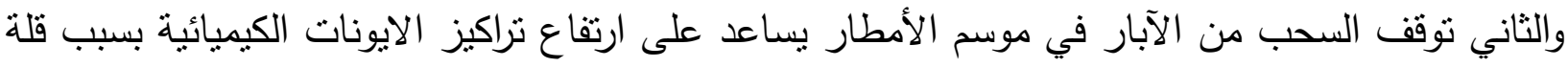

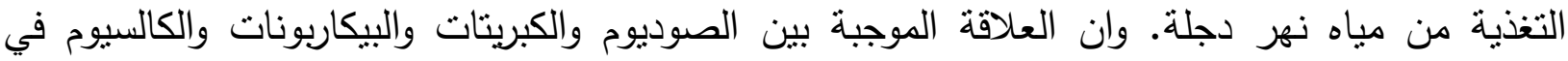
(الجدول 5) تثبير إلى تواجد الصوديوم ضمن المنبخرات العائدة لتكوين الفتحة. أما ايون البوتاسيوم فقد بلغ ولغئ

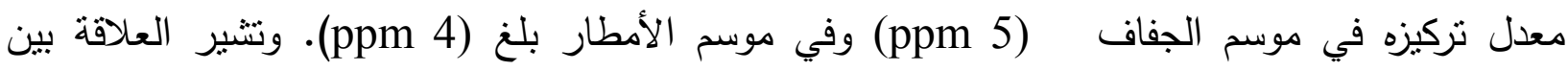
البوتاسيوم والنترات في (الجدول 5) إلى الهصدر الغير طبيعي لهذا العنصر في آبار الدراسة، والمتمنل

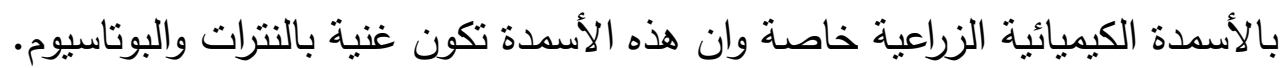

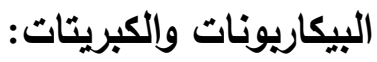

تحتوي جميع المياه الطبيعية على نسبة من البيكاربونات والكبريتات، وتختلف هذه النسبة اعتمادا على

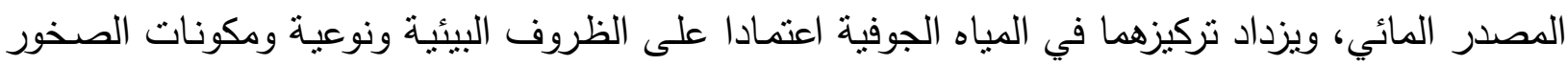

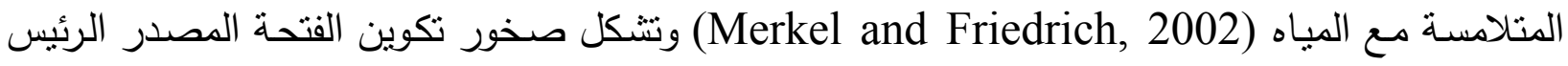

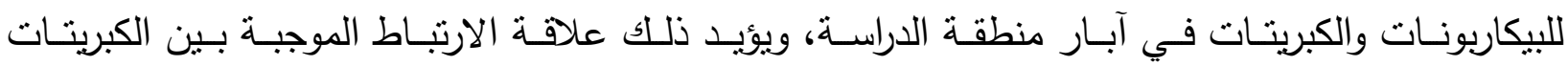

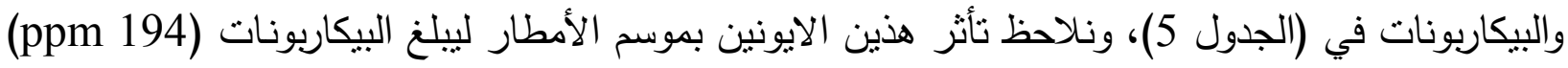

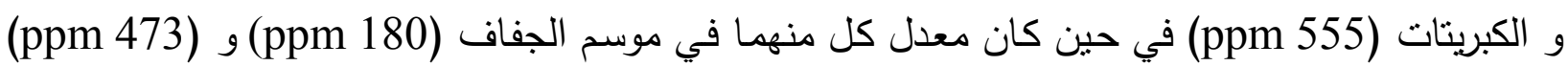
على التوالي.

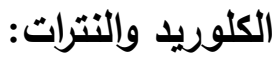

يمتاز هذين الايسونين بقابليـة الذوبان العاليـة، ومسن الصـعب أن يثـتركان في تفـاعلات الترسيب

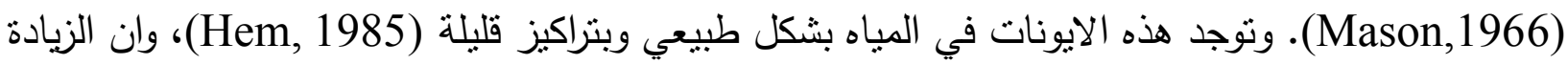

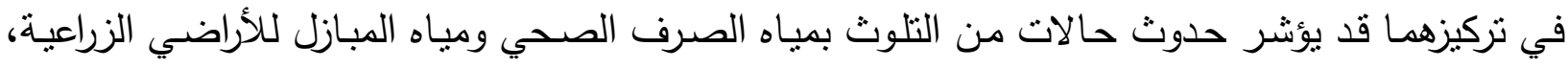

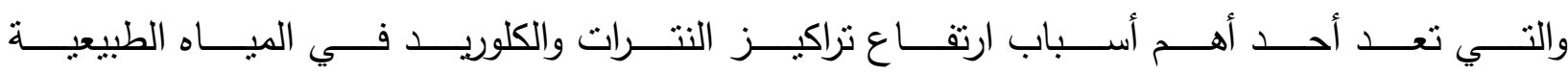
(Heath, 1987) و (Yaan and Miyamoto, 2006). ويلاحظ ازدياد في تركيز كل من الايونين في

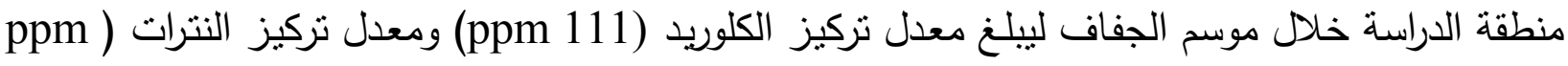

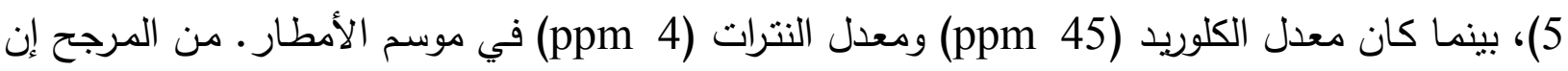

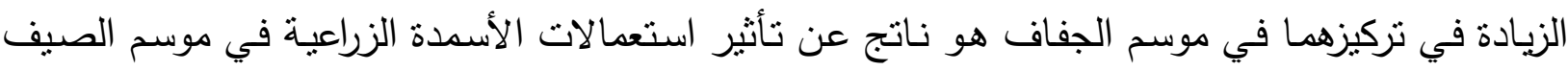

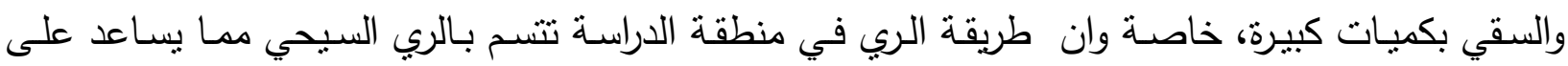


تغلغل مياه الري المحملة بالايونات الكيميائية المتوفرة في الأسمدة الزراعية إلى المياه الجوفية، ويؤيد ذلك

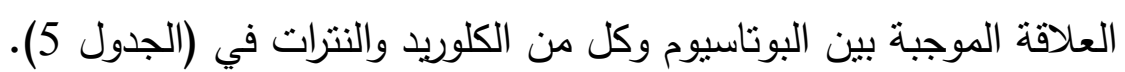
ومن الجدير ذكره إن تراكيز هذه الايونات لا تعتمد على المكونات الصخرية لمنطقة الدراسة وإنما

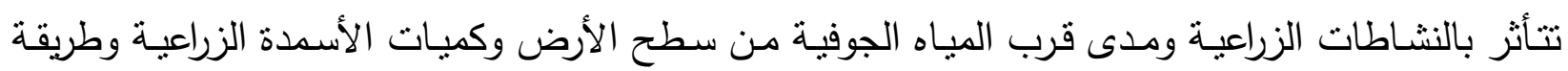

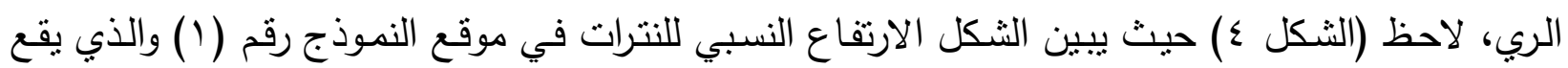

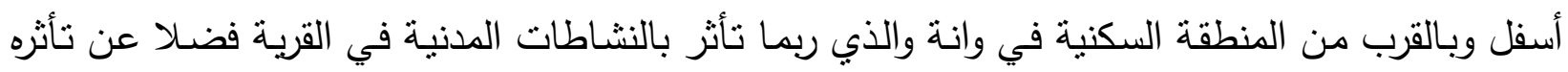

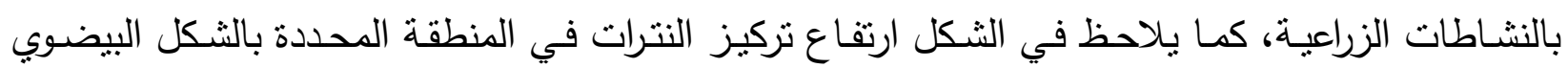

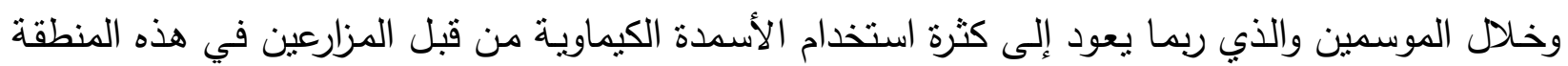
خاصة وان هذه المنطقة تمناز بالتربة المزيجية والرملية ذات النفاذية العالية.

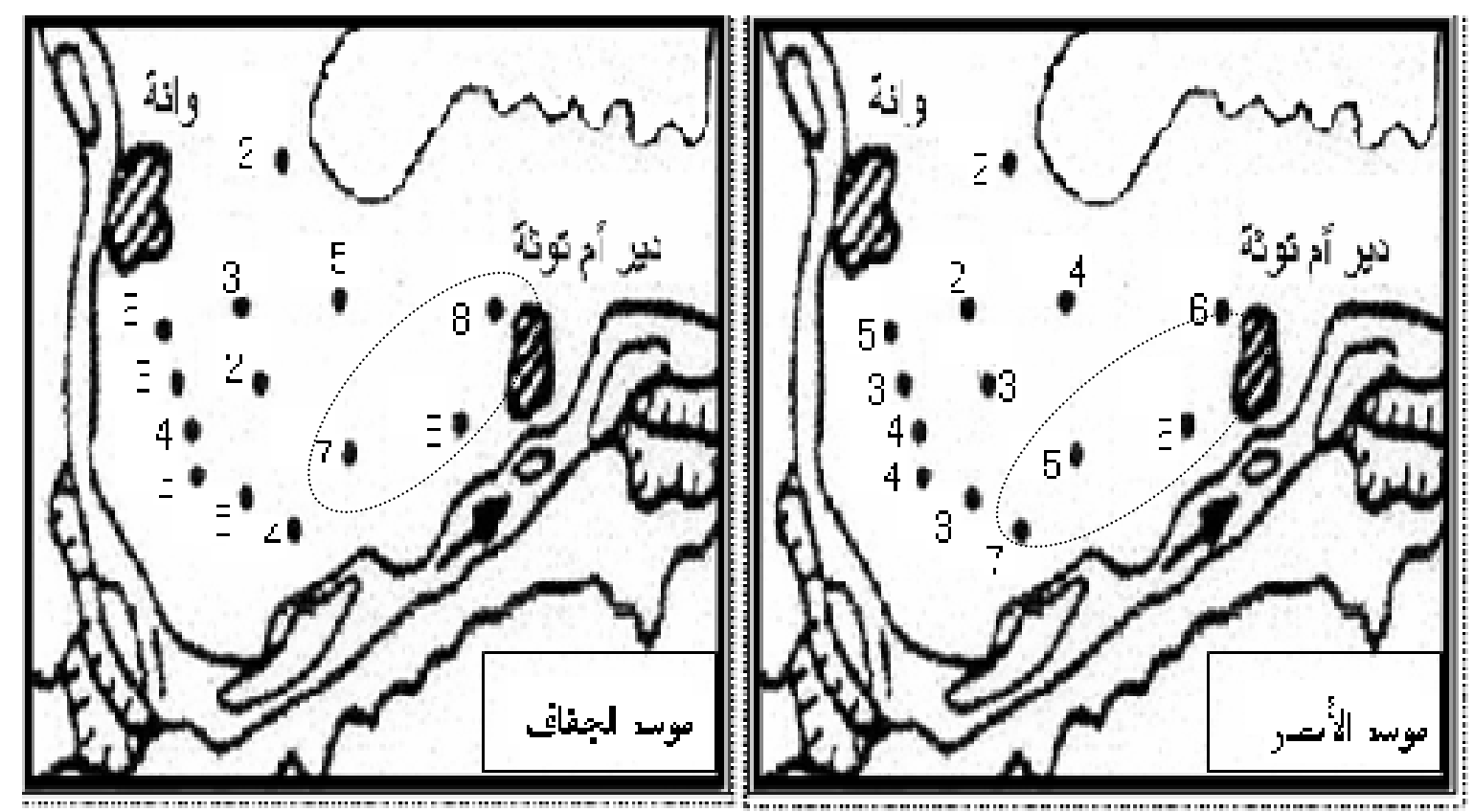

الثكل ؟: مواقع آبار الدراسة موضح عليها نراكيز النترات (NO3) بوحدة (ppm) وخلال فترتي

التحليل الإحصائي:

تم إدخال بيانات التحاليل الفيزيائية والكيميائية لمياه آبار الدراسة وللموسمين معا في البرنامج الإحصائي وتبين من خلال إجراء التحليل العاملي (SPSS)

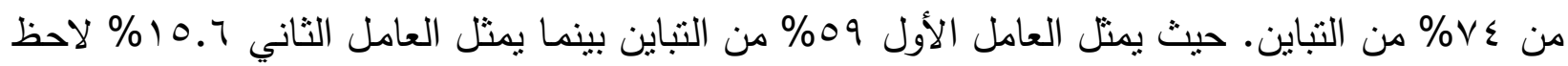

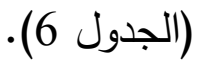


يشكل هذا العامل نسبة كبيرة من مجموع التباين (؟.09\%)، وهو عامل أحادي القطب ويتمنل

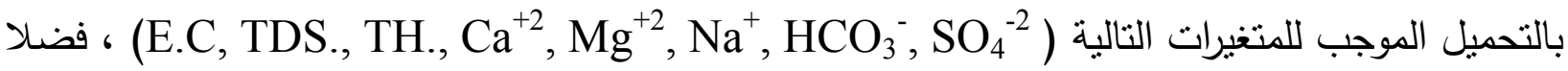
عن الصفات الحقلية للآبار من حيث عمق مستوى المياه (Dep.) والمسافة بين الآبار ونهر دجلة مصدر التغذية الرئيس في المنطقة (Dis)، لاحظ(الثكل 6). ويمثل هذا العامل المكونات الصخرية في المنطقة والمتمنلة بصخور الكاربونات والمتبخرات العائدين لتكوين الفتحة، الذي يعد المصدر الرئيس للايونات

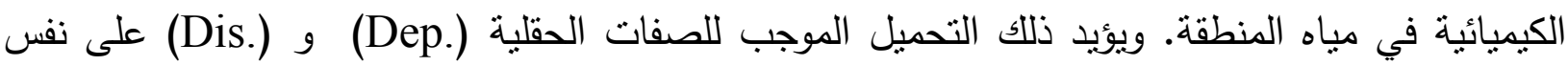
العامل، وهذا أمر طبيعي إذ من المرجح أن تزداد تراكيز الايونات الرئيسة في المياه كلما زادت المسافة بين

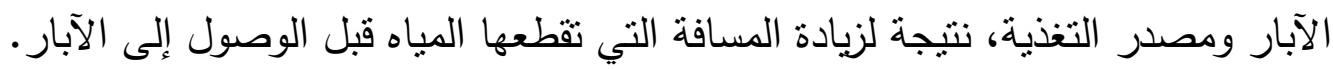

الجدول 6: الحمل (Variance) و و (Eigen values) و و (Communalities) لإمالمل الأول والثاني

\begin{tabular}{|c|c|c|c|}
\hline Oxide & Factor 1 & Factor 2 & Communalities \\
\hline Dep. & .852 & -.017 & 0.726 \\
\hline Dis. & .666 & -.372 & 0.582 \\
\hline T.D.S & .957 & -.169 & 0.944 \\
\hline T.H & .972 & .077 & 0.951 \\
\hline pH & -.088 & -.590 & 0.356 \\
\hline $\mathrm{E} . \mathrm{C}$ & .956 & -.170 & 0.943 \\
\hline $\mathrm{Ca}^{+2}$ & .904 & .142 & 0.837 \\
\hline $\mathrm{Mg}^{+2}$ & .893 & -.019 & 0.798 \\
\hline $\mathrm{Na}^{+}$ & .849 & -.242 & 0.779 \\
\hline $\mathrm{K}^{+}$ & .461 & .772 & 0.809 \\
\hline $\mathrm{HCO}_{3}^{-}$ & .708 & -.239 & 0.558 \\
\hline $\mathrm{SO}_{4}^{-2}$ & .974 & -.102 & 0.959 \\
\hline $\mathrm{Cl}^{-}$ & .545 & .585 & 0.639 \\
\hline $\mathrm{NO}_{3}{ }^{-}$ & .197 & .744 & 0.592 \\
\hline Eigen values & 8.284 & 2.188 & \\
\hline Variance(\%) & 59.169 & 15.632 & \\
\hline Cumulative(\%) & 59.169 & 74.801 & \\
\hline & & &
\end{tabular}

وبالتالي زيادة عمليات الغسل والإذابة لصخور وفناتيات صخور تكوين الفتحة في منطقة الدراسة، وهذا

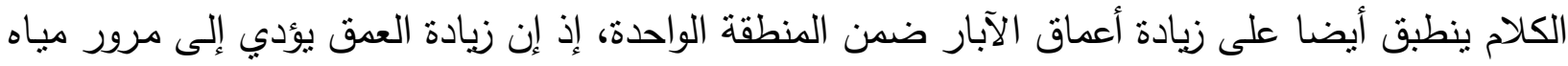

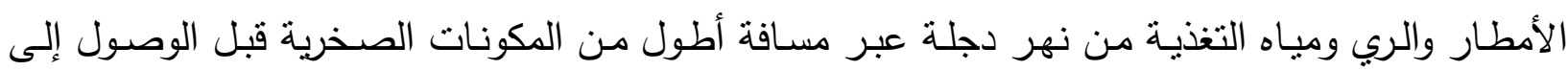
مستوى المياه الجوفية، الأمر الذي يساعد على زيادة فرصة الإذابة وبالتالي زيادة تركيز الايونات الرئيسة،

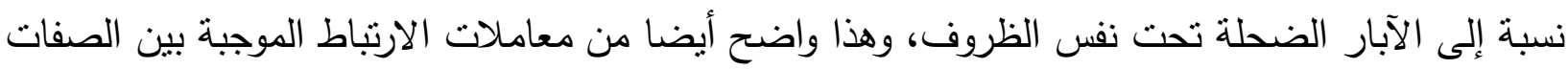

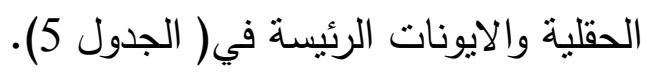




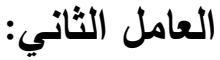

يشكل هذا العامل (10.7 1\%) من مجموع التباين، ويعد اقل نأثيرا من العامل الأول، وينحصر نأثيره بشكل رئيس على التحميل الموجب لايوني البوتاسيوم والنترات، ويتشارك مع العامل الأول في التأثثر على لئى

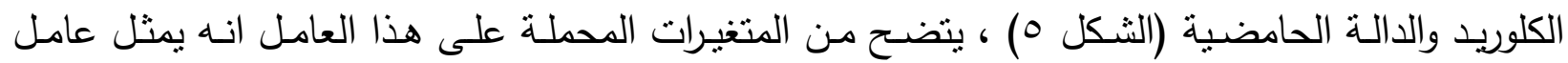

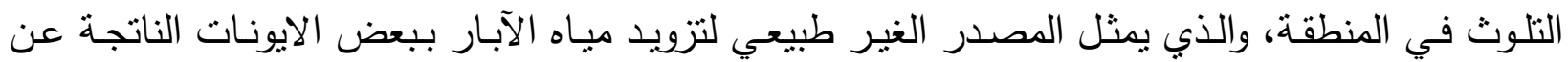

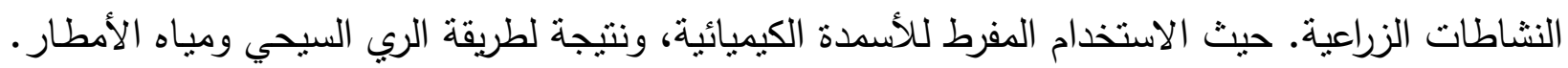
يتم وصول بعض الايونات من المكونات الرئيسة للأسمدة الكيميائية إلى اليياه الجوفية.

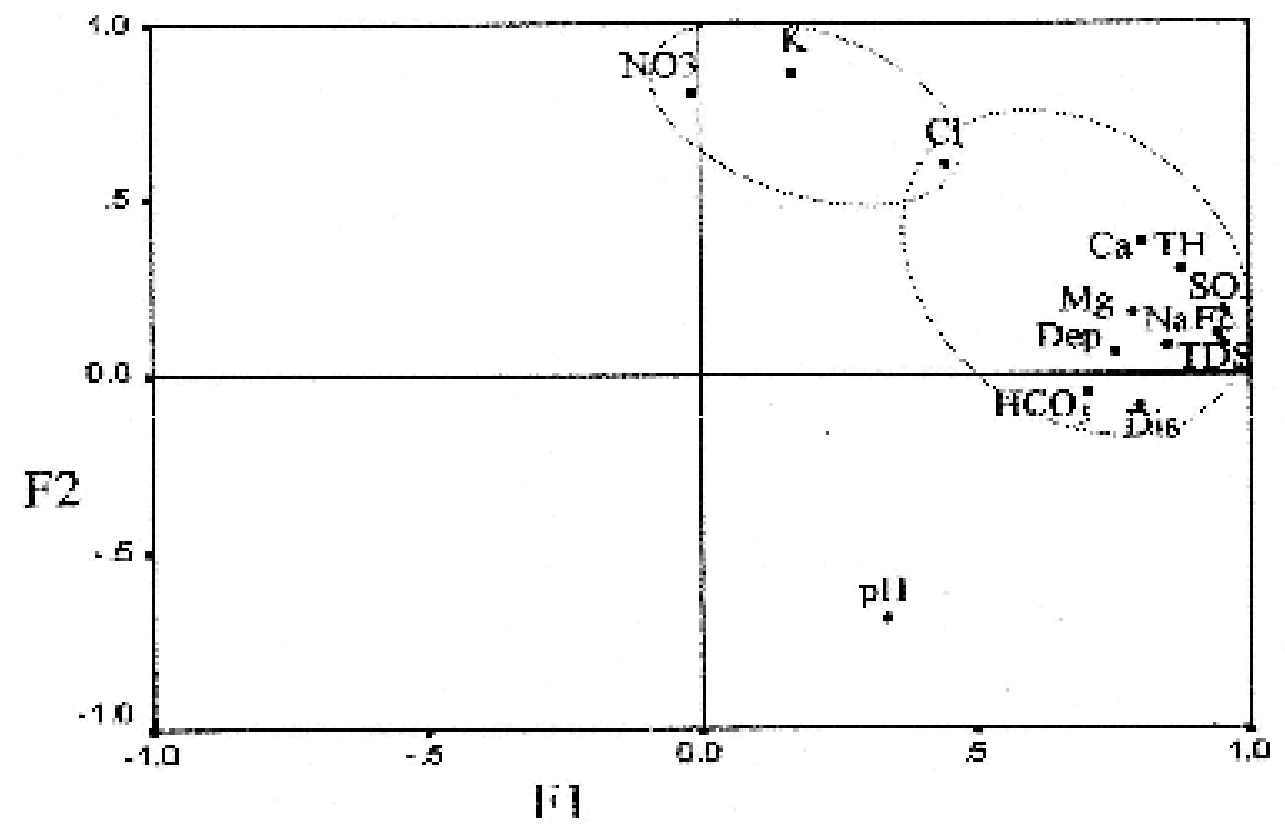

الثكل ه : مساقط نقاط العامل الأول والثاني بعد التدوير

وعلى العموم يمكن تلخيص نتائج التحليل ألعاملي لبيانات مياه آبار الدراسة، بان هناك عاملين رئيسين يتحكمان بهيدروكيميائية المياه في المنطقة، العامل الأول والمسيطر هو عامل طبيعي ينمثل بالمكونـات

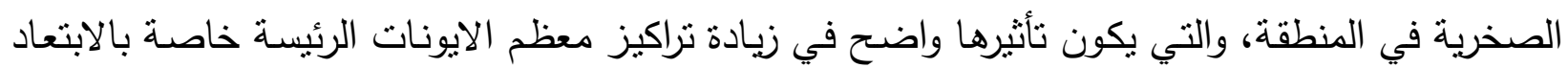

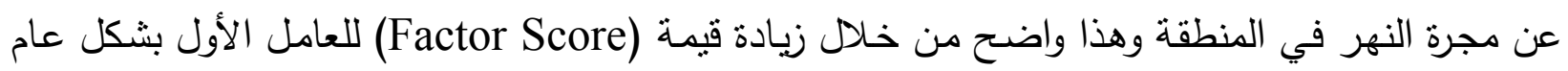

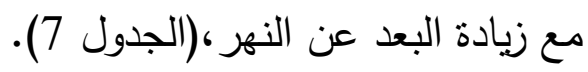
أما العامل الثاني فهو عامل غير طبيعي(عامل التلوث) ويتمتل بالنشاطات الزراعية في المنطقة، وهذا العامل لا يعتمد على البعد أو القرب عن النهر ولا على جيولوجية المنطقة وإنما يتأثر بكمبات السماد المستخدم للأراضي الزراعية. 
الجدول 7: (Factor Score) للعاملين الرئيسين لآبار الدراسة

\begin{tabular}{|c|c|c|c|c|}
\hline \multicolumn{2}{|c|}{ موسم الأمطار } & \multicolumn{2}{|c|}{ موسم الجفاف } & \multirow{2}{*}{ رقم البئر } \\
\hline Factor Score 2 & Factor Score 1 & Factor Score 2 & Factor Score 1 & \\
\hline-0.8560 & -1.3090 & 0.7042 & -1.8098 & 1 \\
\hline-1.3277 & -0.7488 & -0.5097 & -1.1166 & r \\
\hline-0.4989 & -0.5000 & 0.3328 & -0.7627 & r \\
\hline-0.3194 & -0.2020 & 0.2725 & -0.5609 & $\varepsilon$ \\
\hline-0.6369 & 0.1977 & 0.7372 & -0.2666 & 0 \\
\hline 1.2178 & -1.0521 & 0.2769 & -1.2472 & 7 \\
\hline-0.2673 & 1.2775 & 2.4926 & 0.6767 & v \\
\hline-0.9253 & 1.8379 & 0.6094 & 1.6725 & $\wedge$ \\
\hline-1.5372 & -0.0469 & -0.7259 & -0.1926 & 9 \\
\hline-1.0551 & -0.2391 & -0.5293 & -0.3866 & 1. \\
\hline-0.2275 & 0.4876 & 1.5192 & 0.0634 & 11 \\
\hline-0.9210 & 1.5630 & 0.1671 & 1.0733 & ir \\
\hline 0.0933 & 1.3571 & 1.9142 & 0.2342 & ir \\
\hline
\end{tabular}

تم استخدام طريقة بايير لتصنيف مياه آبار الدراسة، حيث تعد هذه الطريقة من أكثر الطرق استخداما في التصنيف الهيدروكيميائي للمياه (Walton,1970). وتبين من استخدام هذا التصنيف إن مياه البئرين

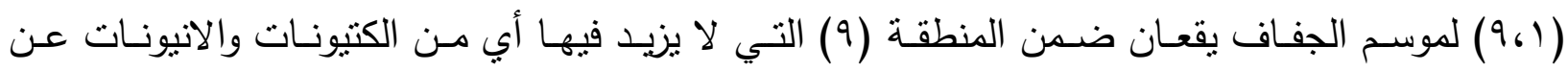

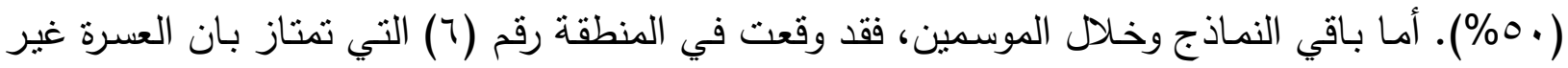

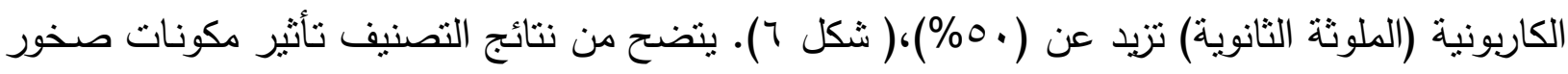

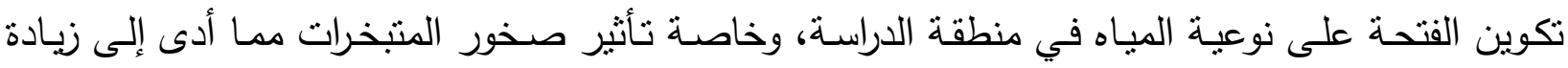

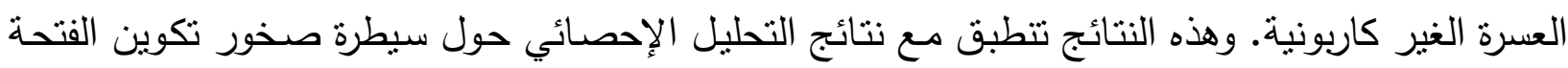
على هيدروكيميائية مياه المنطقة. 


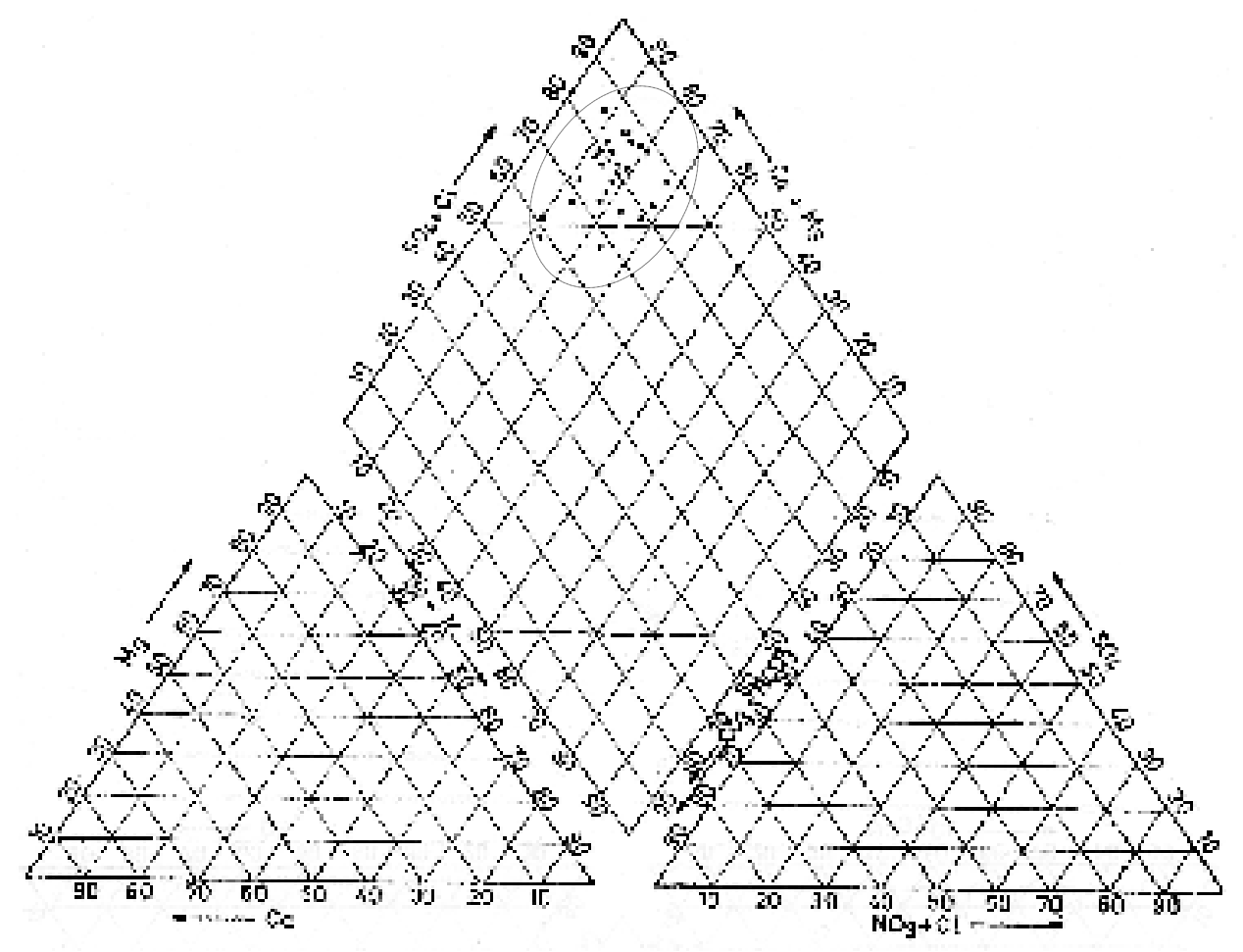

الثكل 7: مخطط بايير موضح عليها نماذج الدراسة.

صلاحية المياه لأغراض الري:

إن مياه منطقة الدراسـة تستخدم في ري المحاصبل الحقلية بشكل رئيس، لذلك فقد تم التركيز على

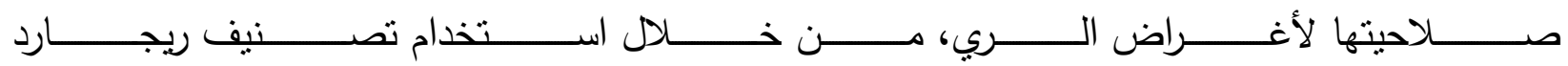

الذي يعتمد على أهم عاملين من العوامل المؤثرة على نوعية مياه الري، وهما المقدار الكلي للملوحة معبر عنه بالتوصيل الكهربائي، ونسبة امتصاص الصوديوم (SAR) التي تعد مـن العوامـل الهيدروكيميائية المههـة والتي لها تأثير ضـار على التربـة (Todd,1980). ويقاس (SAR) بوحدة epm للايونات في المعادلة التالية.

$\mathrm{SAR}=\mathrm{Na} /((\mathrm{Ca}+\mathrm{Mg}) / 2)^{0.5}$

وبتضح من (الشكل V) إن مياه منطقة الدراسة، وخلال موسمي الجفاف والأمطار تقع ضمن الحقلين C2S1

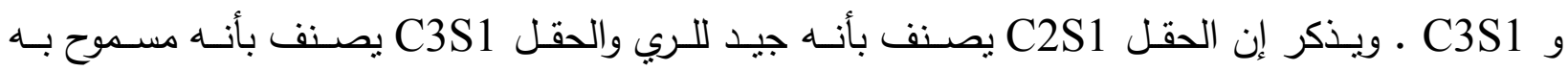


للاستخدام في الري. وبهذا فـان جميع الآبـار المدروسـة في منطقة الدراسـة تصـلح لأغراض الري حسب تصنيف ريجارد.

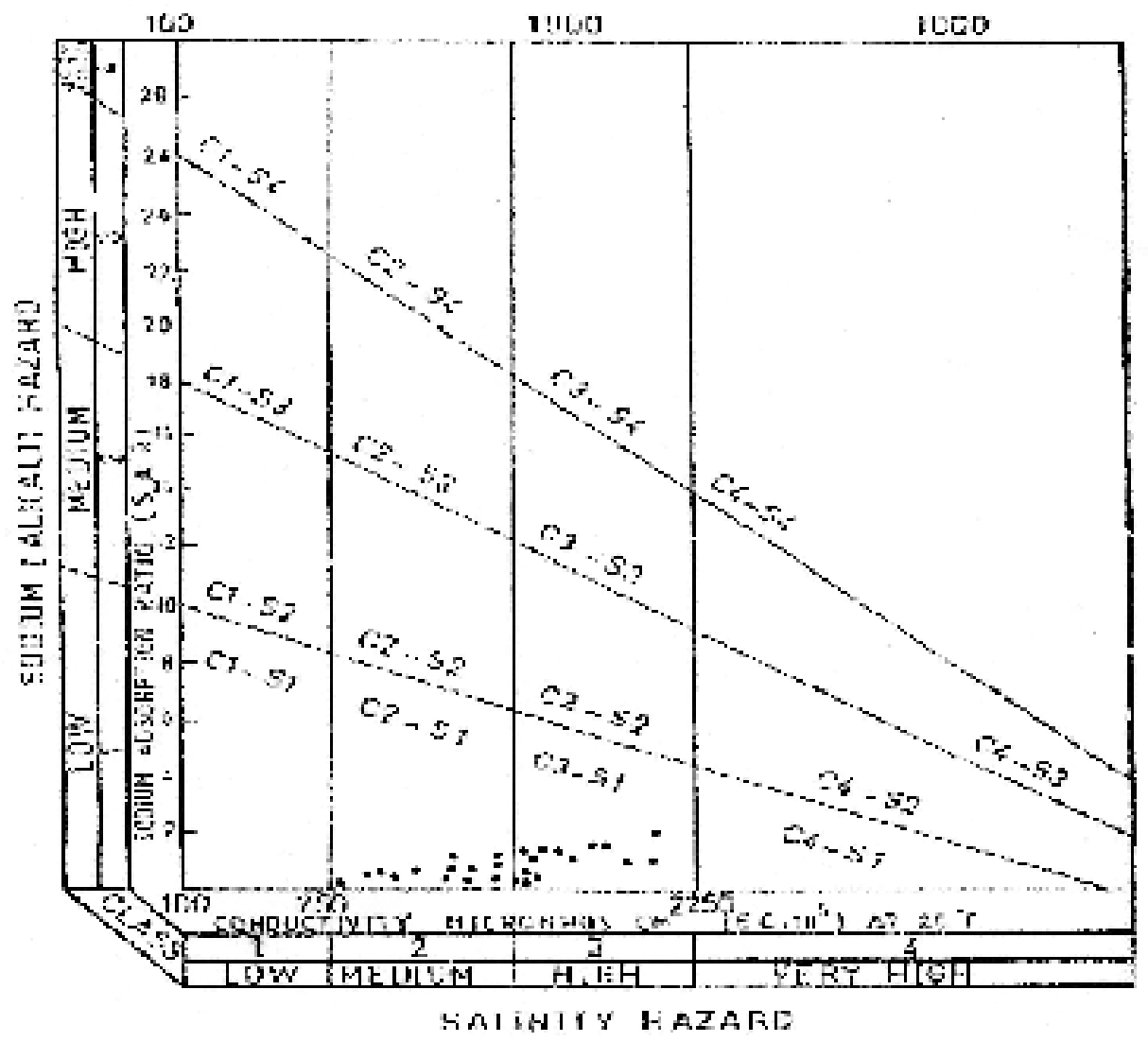

الشكل V : تصنيف ريكارد لمياه الري موضتح عليه نماذج

الاستتتاجات

ا - سيطرة المكونات الصخرية لتكوين الفتحة على هيدروكيميائية المياه الجوفية في منطقة الدراسة. r- نأثز مياه آبار الدراسة بالنشاطات الزراعية في المنطقة. ب- زيادة العسرة غير الكاربونية في مياه الآبار بتأثير صخور المتبخرات العائدة لتكوين الفتحة. ع - تتخفض تراكيز الايونات الكيميائية في الآبار القربية من نهر دجلة بسبب قرب مصدر التغذية. ه- صلاحية مياه آبار الدراسة لأغراض الري. 


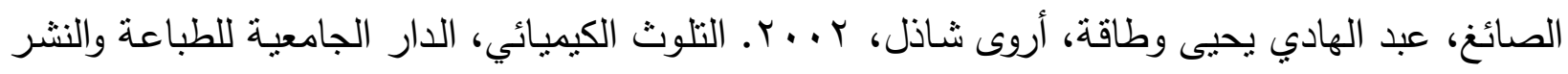

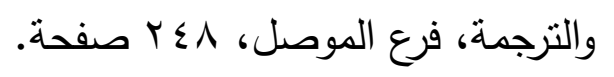

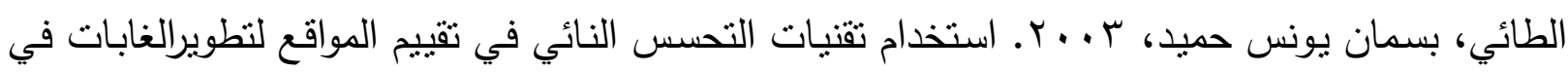

نينوى، أطروحة دكتوراه غير منشورة، كلية الزراعة والغابات، جامعة الموصل، مبر ب صفحة.

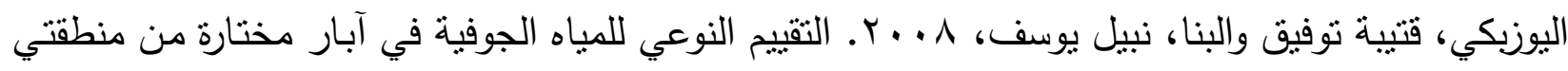

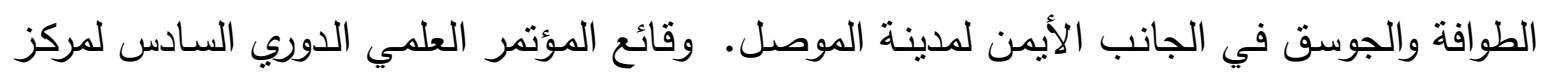

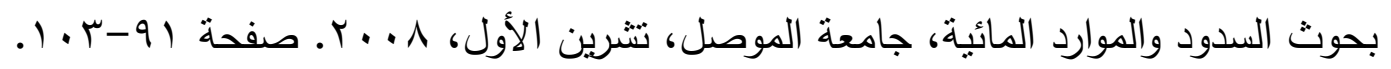

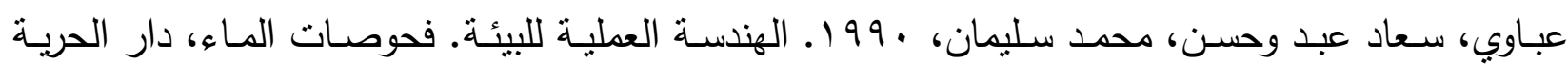

للطباعة والنشر ، و ب ب صفحة.

مصطفى، معاذ حامد، V . . . . التباين النوعي لمصـادر المياه في موقع قرية حسن شـامي. وقائع المؤتمر

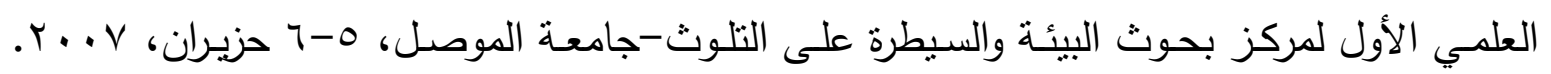

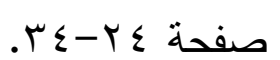

\section{المصادر الأجنبية}

Al-Dabbagh, T. H. and Al-Naqib, S. Q., 1991. Tigris River Terraces Mapping in Northern Iraq and the Geotechnical Properties of the Youngest Stage. Quaternary Engineering Geology, 25 ${ }^{\text {th }}$ Annual Conf. of Eng. Group, Geol.

Soc., Heriot-Watt Univ., Sept. 10-12, 1989. Spec., Publ., pp. 603 - 609.

Bouwer, H. 1978. Ground Water Hydrology. MC Graw-Hill New York, 480 p.

Devilliers, S. 2005. The Hydrochemistry of Rivers in Kwazulu -Natal. Water SA, Vol. 31, No. 2, pp. 193 - 198.

Fitts, C. R. 2002. Groundwater Science, Academic Press, 450 p.

Freeze, R. A. and J. A. Cherry. 1979. Groundwater, Prentice Hall, Englewood Cliffs, N.J.

Heath, R. C. 1987. Basic Ground-Water Hydrology, Fourth printing, USGS., 84 p.

Hem, J. D. 1970. Study and interpretation of the chemical characteristics of natural water, $2^{\text {nd }}$ Edition U.S. Geological Survey Water Supply Paper, 1473, 363 p.

Hem, J. D. 1985. Study and interpretation of the chemical characteristics of natural water, $3^{\text {rd }}$ Edition U.S. Geological Survey Water Supply Paper 2254. 263 p.

Jenkins, D., Snoeyink , L., Fergus, J. F. and Leckie, J. O., 1980. Laboratory manual water chemistry, John Wiley and Sons, New York, 183 p.

Langmuir, D. 1997. Aqueous Environmental Geochemistry. Prentice Hall, USA, $600 \mathrm{p}$.

Manahan, S. E. 2005. Environmental chemistry, CRC press, $8^{\text {th }}$ ed., Washington, USA. $783 \mathrm{p}$.

Mason, B. 1966. Principals of Geochemistry. $3^{\text {rd }}$ Edition. Willey International Publication. 324 p. 
Merkel, B. J. and Friedrich, B. P. 2002. Groundwater Geochemistry, Springer Berlin, $191 \mathrm{p}$.

Sen, Z. 2008. WADI HYDROLOGY, CRC Press, Taylor and Francis Group, $339 \mathrm{p}$.

Todd, D. K., 1980. Ground Water Hydrology. John Wiley\& Sons, Inc. Toppan Printing Company (Ltd). New York and London, 535P.

Todd, D. K. and Mays, L., 2005. Ground Water Hydrology, (3 ${ }^{\text {rd }}$ ed.) John Wiley and Sons,Inc, $636 \mathrm{p}$.

Walton, W. G. 1970. Ground Water, Resource Evaluation, Mc Graw Hill Int. Book Comp. New York, 664 p.

Yuan, F. and Miyamoto, S. 2006. Changes in major Element hydrochemistry of the Pecos River in the American South West Science 1935. 